
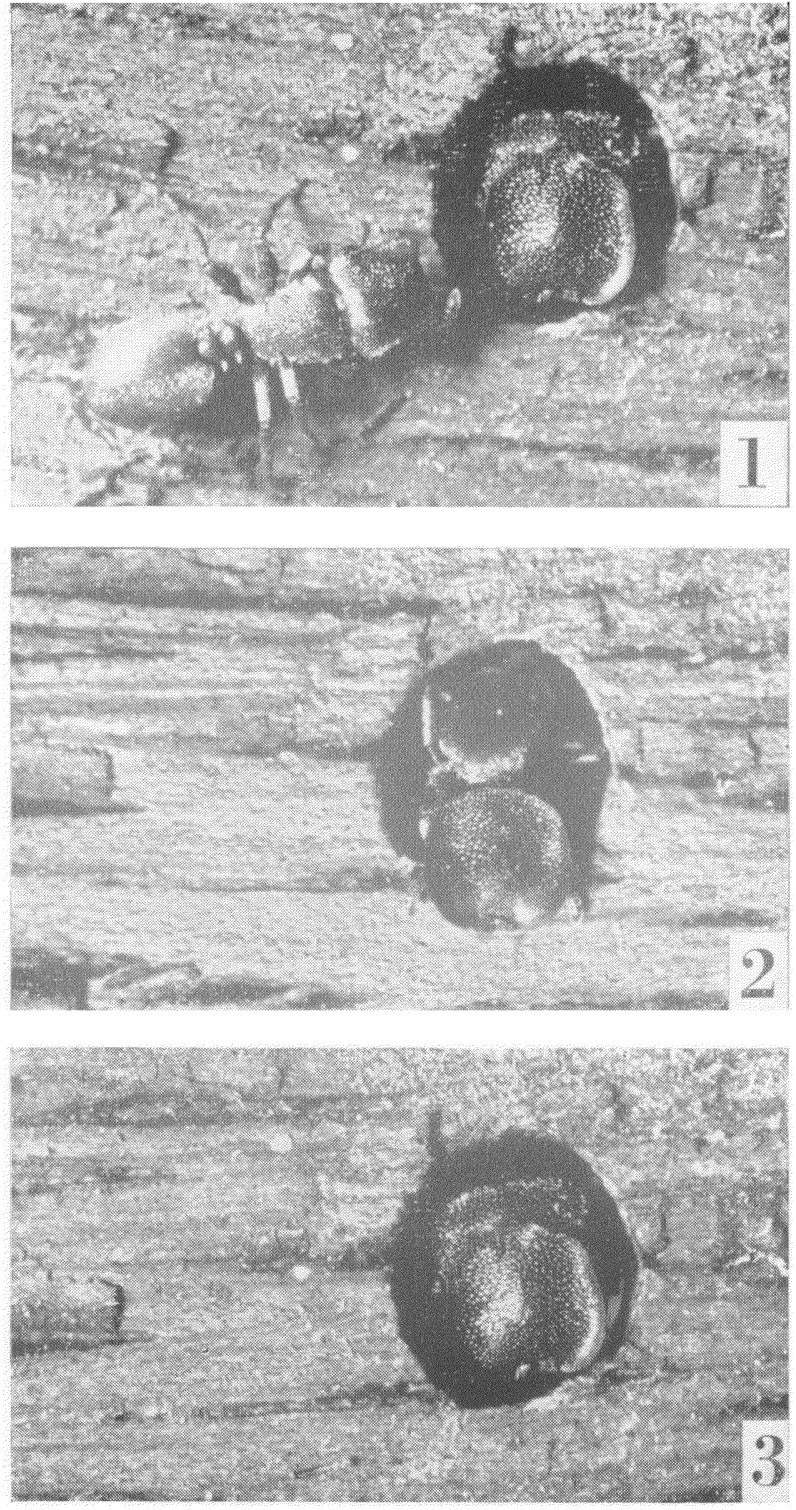

Creighton - Cryptocerus

Figures 1-3 

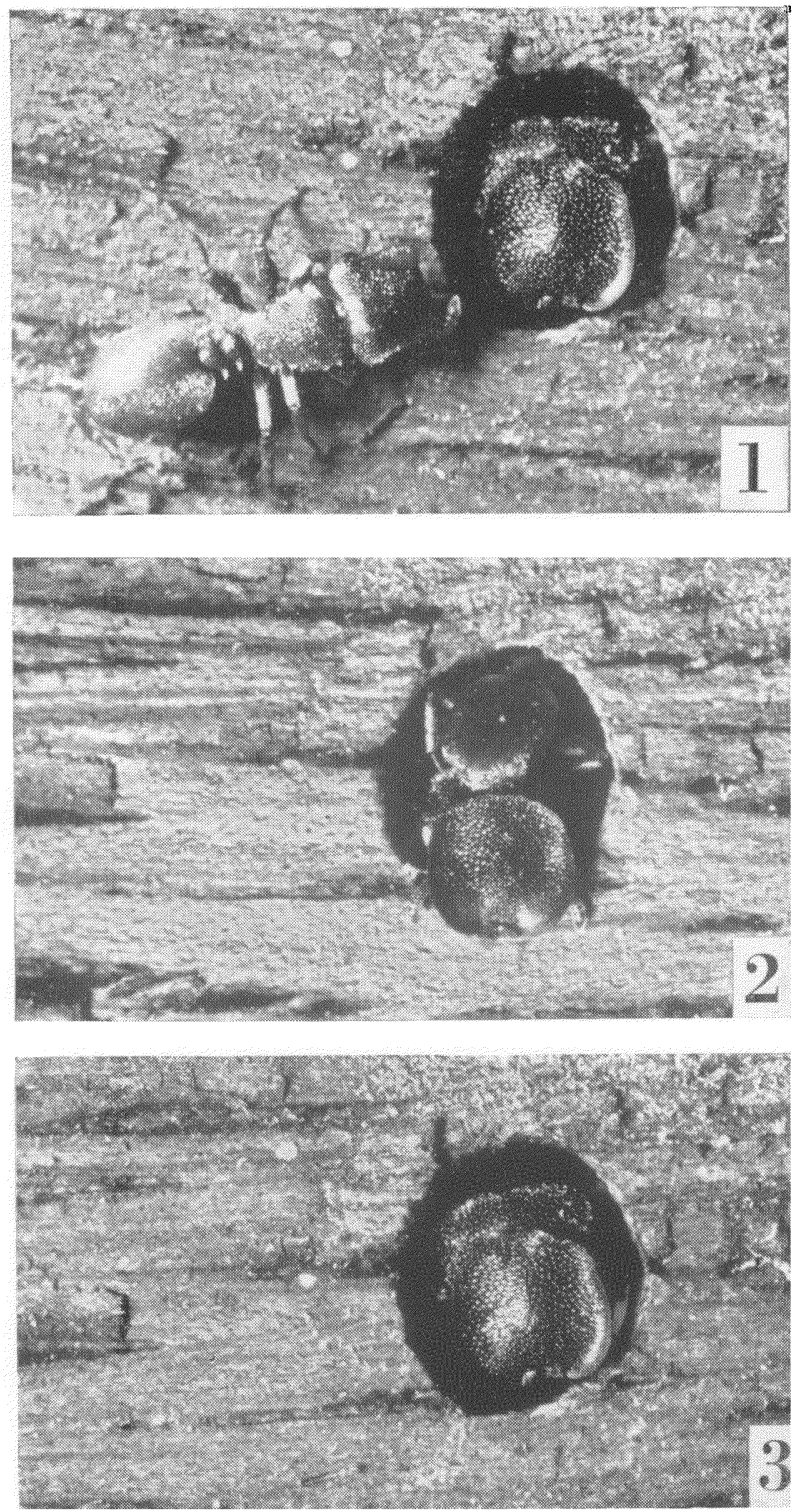

Creighton - Cryptocerus

Figures 1-3 


\title{
PSYCHE
}

$\begin{array}{lll}\text { Vol. } 70 & \text { September, } 1963 & \text { No. } 3\end{array}$

\section{FURTHER STUDIES ON THE HABITS OF CRYPTOCERUS TEXANUS SANTSCHI (HYMENOPTERA: FORMICIDAE)*}

\author{
By Wm. S. CReighton ${ }^{1}$ \\ Department of Biology, City College, N'ew York
}

The observations presented in this paper were made on a colony of Cryptocerus texanus Santschi secured on December 19, I96I at a station 21 miles north of Mathis,. Texas. This colony was placed in small Janet nests and taken to the Southwestern Research Station of the American Museum of Natural History near Portal, Arizona. There it was observed for three and a half months. During this period Dr. Mont Cazier furnished much helpful information about the beetle larvae in whose burrows texanus lives and Mr. Martin Mortensen took the photographs included in this paper. I wish to thank Dr. Cazier and Mr. Mortensen for their help.

In 1954 Dr. R. E. Gregg and the writer published a study of the distribution and habits of Cryptocerus texanus (I). A large part of this study was concerned with the phragmotic activities of the texanus major. These responses as well as other activities discussed in the paper were shown by specimens in observation nests. Although the writer hoped to observe the activities of free nests of texanus, attempts to do so have met with no success so far. Nevertheless it has been possible to set up observation nests which permit the ants much greater freedom of action than did those used in our earlier study.

Before discussing these nests I wish to consider certain characteristics of texanus which largely determine its choice of nest sites. In common with a number of arboreal ants which occur in the southwest (species in the genera Pseudomyrmex, Crematogaster, Leptothorax and Camponotus) texanus does not construct its own nest passages. It may be too much to state that texanus is incapable of tunneling through the wood in which it lives, but there is abundant evidence to show that it does not ordinarily do so. Instead it utilizes burrows made by wood-

${ }^{1}$ Professor Emeritus, City College, New York.

*Manuscript received by the editor January 28, 1963. 
boring beetle larvae. The burrows most often selected are those of anobiids, bostrychids and some of the smaller buprestids. Under normal conditions each burrow consists of a long, slender, unbranched tube which opens to the outside at one end and terminates in a blind pocket at the other. The portion of the burrow just behind the opening curves inward but the rest of it roughly parallels the long axis of the branch. A branch whose diameter is $4 \mathrm{~cm}$. or more may be traversed by several closely adjacent but completely separate burrows. This arrangement permits a number of beetle larvae to occupy the same branch without interference. By the time that the adult beetle emerges the branch is dead and the burrow is partially filled with detritus, which is mainly composed of small bits of cellulose that have passed through the gut of the beetle larva. The consistency of this material is similar to that of fine, tightly compacted saw-dust. This detritus must be removed before the ants can occupy the burrow, but its removal is not difficult and the process has little in common with the driving of a passage through sound wood. When the detritus has been removed what is left is a prefabricated burrow whose walls consist of hard, sound wood and whose entrance is of a size that can be occluded by the major. The branches in which texanus nests are largely or entirely devoid of bark. Branches which do not lose their bark are usually softened by dry rot. Such rotten branches often contain burrows but the ants seldom occupy them.

The behavior just discussed produces the problem of polydomy in texanus. A branch which has been extensively tunneled may contain several groups of texanus workers each living in a separate burrow. If it can be shown that only one of these groups contains a queen the probability is that the several burrows contain parts of a single, polydomous colony. But when each group contains one or more queens it is impossible to state whether one is dealing with several separate colonies or a single polydomous colony. The matter becomes even more complicated when several adjacent branches house groups of texanus workers. This was true of the population on which this study was based. The ants occupied burrows in the stubs of six dead branches, all attached to a single living branch of a live-oak (Quercus virginiana $\mathrm{Nee}$ ). The total population of the six stubs consisted of approximately 275 individuals of which 23 were queens. Since the number of queens in each stub varied from two to five, it was impossible to say whether the six groups were separate colonies or parts of a single polydomous colony. As it was advantageous to have a number of equivalent groups for the work that was contemplated, it was decided to proceed on the 
latter assumption. The I 8 queens which survived extraction were arranged in nine pairs and each pair was installed in a plaster observation nest with about twenty-five workers selected at random. No friction developed in any of the groups thus established and it was found that the groups could be reshuffled at will. It was not until much later, when some of the groups had been isolated for months, that they began to act as separate entities. Even then the groups would combine after a brief period during which an avoidance reaction was displayed. Since this combination was a voluntary response on the part of groups which could have nested separately, it seems probable that the original population was a single polydomous nest.

Through unusual good fortune one of the majors remained in the occluding position when the stub containing that portion of the colony was split open. The part of the stub which contained the nest opening and its adjacent nest passage was saved. The nest entrance was an oval with a long axis of $2.8 \mathrm{~mm}$. and a short axis of $2.65 \mathrm{~mm}$. With these proportions in mind it was easy to supply a branch containing a burrow whose entrance was of the proper size. After it was certain that this branch contained no other arboreal ants, it was placed on the floor of a two gallon aquarium together with one of the occupied Janet nests. The cover of the Janet nest was then removed and a glass top was sealed onto the aquarium with masking tape. The texanus workers at once began to explore the aquarium and soon abandoned the Janet nest for the burrow in the branch. With one exception the groups remained in the burrows. The one group which failed to do so had been given a branch which was rotten on the inside although it was sound to external appearances. When this group was given a sound branch they accepted it without further difficulty.

One interesting feature of the aquarium nests was that they offered natural conditions for nest occlusion. It is gratifying to report that the phragmotic responses described in our I954 study are essentially the same as those of a major which is occluding a natural burrow entrance. In the main this is also true of the behavior of the minor but one interesting difference often occurred. In our earlier studies the minor always entered the nest by crawling over the dorsum of the crouching guard (Plate I, figs. I-3). As the glass top of the observation nest formed the roof of the passage, less traction was furnished by this glass roof than by the dorsum of the guard. But in a natural nest this is not true and the minors would often enter the nest by walking over the roof of the passage rather than over the dorsum of the guard. When this occurs the dorsal surface of the entering minor 
is very close to that of the crouching guard and may be in actual contact with it. Another advantage of the aquarium nests was that they permitted limited foraging. If free colonies of texanus forage as did those in the aquaria, then texanus forages only in the daytime. Foraging appears to be initiated by the morning increase in light intensity but it will not occur unless the temperature is $70^{\circ} \mathrm{F}$. or higher. Much of the foraging was done by the medias and minors but the majors were not restricted to the nest. This led to another type of response when the major on guard at the nest entrance had to admit another major, for the usual crouching reaction of the guard will not furnish enough space to allow a major to enter. When this was necessary the guard came out of the nest entrance. The returning major then entered the burrow head first, after which the guard backed into the entrance and assumed the occluding position. In the aquarium nests the guard was not continually on duty. This may have been because no strange ants were present. The writer has observed the same behavior in Camponotus (Myrmaphaenus) ulcerosus Wh. (2), whose major assumes the phragmotic position only when other ants are in the vicinity of the nest entrance.

In our 1954 publication it was stated that texanus sometimes forages on the ground. This may be true but it is now clear that such foraging has not been conclusively demonstrated. The aquaria nests were kept supplied with fresh live-oak twigs and the ants constantly walked about on their leaves. Although texanus is not an agile ant, it is surprisingly sure-footed. Even so foraging workers would sometimes lose their balance and fall to the floor of the aquarium. When a worker lands on its back, as it often does, it rights itself in an unvarying fashion. Both the head and the gaster are lifted above the surface on which the ant is lying until the body forms an arc. Thereafter one of the hind legs is extended and the body is rocked until it turns on one side. In the scores of times that the ants were seen to regain their footing, the process never varied in the slightest particular. While the flattened dorsum of texanus undoubtedly makes it difficult to right the body from an inverted position, this will not explain why the righting reaction is so stereotyped. But this unvarying righting reaction can be explained if the ants have had occasion to right themselves so often that the most efficient method of righting has become an integral part of their behavior. This implies that the ants frequently fall from the trees in which they live, a view that is supported by their actions in the aquaria. For if the ants cannot always maintain their footing on leaves that are unaffected by wind, then every strong 
gust must displace some of the foraging workers of a free nest. The victims of such accidents undoubtedly return to the nest but to do so they have to traverse the ground at the base of the tree. It is easy to interpret this action as the return of a forager which, in a sense, it is. But when workers of texanus are found wandering on the ground at the base of a tree this does not constitute proof that the foraging has been terrestrial. The writer fell into this trap in 1954, for at that time it was not considered that the presence of texanus workers on the ground below a tree might be accidental.

While the nests in the aquaria showed many advantages they had one serious defect. It was impossible to see what was going on in the burrows. There seemed to be no reason why this defect might not be remedied if the ants could be made to accept "burrows" in which one side was closed with glass. Accordingly, small blocks of seasoned oak $10.5 \times 3.5 \times 2.5 \mathrm{~cm}$ were secured. A shallow groove about $7 \mathrm{~cm}$. long was cut on one side of the block and at one end of this groove a hole was drilled to the opposite side of the block. By using a drill 3/32 of an inch $(2.38 \mathrm{~mm}$.) in diameter and by drilling at an angle to the surface, an oval nest opening $2.75 \times 2.50 \mathrm{~mm}$. was produced. While this was slightly smaller than the natural nest entrance, the size difference caused the ants no difficulty. After the oak block had been drilled the face with the "burrow" was placed against the front pane of the aquarium and the block was held in this position by a rim of paraffin. Light was excluded from the "burrow" by a piece of cardboard taped on the outside of the glass opposite the oak block. The ants had access to the "burrow" through the drilled hole which opened into the aquarium. The ants were much more hesitant to accept these passages than those in branches. In order to get them to enter the passage it was usually necessary to chill some members of the group to immobility and insert them through the nest opening. If the opening was plugged for several hours thereafter the workers inside the passage became accustomed to it and on their release would lead the remainder of the group into the passage. Once the ants had established themselves in the passage they seemed thoroughly satisfied with it. Some of the ants lived in the oak blocks for months.

One surprising fact was apparent as soon as the colony had established itself in the passage. Although the length of the passage was about $7 \mathrm{~cm}$., the ants preferred to pack themselves tightly into the outer half of it. They would rarely go into the inner half of the passage and they would never stay there. As far as motility is concerned this packing is very awkward, for only individuals at either 
end of the mass can move freely. Those near the middle of the mass are usually unable to move at all. When the ants have formed this close-packed mass it is difficult to get them to move out of it. Illumination with a brilliant spot of light, unless long continued, will do no more than make the ants shift position slightly. This packing appears to be maintained continuously. For a period of several days the cardboard covers of the nests were replaced by pieces of red cellophane. The ants could thus be observed at any time without exposing them to light. Except for the egress and return of foragers the ants remained close-packed and quiescent during this entire period. The writer can offer no explanation for this behavior but it accords well with what has been noted when free colonies are exposed. From the standpoint of observation it is unfortunate, for it greatly increases the difficulty of keeping a close check on the brood.

Early in this study it became apparent that few of the feeding responses of texanus are normal when the ants are confined in Janet nests. Much the same conclusion had been reached in our I954 study, when some of the colonies in Field nests had been kept alive for more than a year on a diet of maple syrup or honey mixed with egg yolk. But it was obvious that this food could not be obtained under natural conditions and equally obvious that the ants had little liking for such food even though they could subsist on it. Since no more acceptable food had been found, the Janet nests containing the Mathis colony were supplied with maple syrup or honey. The ants soon demonstrated that they preferred honey to maple syrup and honey became their sustaining diet during a period when they were given as wide a variety of small arthropods as could be secured. The arthropods were spiderlings, mites, collembolans, newly emerged mantids, nymphal coccids, membracids and bugs, termites, small beetles and the larvae of several species of arboreal ants. The reaction of the texanus workers to these arthropods varied. Some they attacked and cut to pieces, some they tried to discard and some they ignored. When the victims were cut to pieces the fluids which exuded from them were occasionally imbibed by the attacking texanus workers. But as soon as the victim had been immobilized or killed they rarely paid any further attention to it. This behavior was so strikingly different from that shown by most entomophagous species that, even admitting that it may have been abnormal, there was nothing about it to suggest that arthropods form a part of the diet of texanus. On the other hand this behavior could readily be regarded as a defense response which would rid the nest 
of an unwelcome intruder and later developments appear to confirm this veiw.

It was soon found that the ants would gorge themselves with honey until the posterior segments of the gaster were visibly distended to the rear. This response seems to have been due to a need for fluids and not to a fondness for honey. The presence of honey in the feeding chambers favored the growth of mould. To reduce mould growth to a minimum the nests were kept dry enough to prevent condensation and it is likely that the only fluids that the ants secured were those furnished by the food in the nests. Thus it seems correct to state that the conditions in the Janet nests were such that the ants were subjected to a sort of forcible feeding. The females also gorged themselves with honey and soon began to lay eggs. These were eaten by the workers almost as fast as the queens laid them. This obvious protein lack was corrected by giving the ants mantis eggs which had been sliced open. The ants would gorge themselves on the liquid contents of the mantis eggs and thereafter stopped eating their own eggs. As a result brood was produced, some of which was carried through to the pupal stage. It should be noted that both the egg-laying of the texanus queen and the development of her brood is slow, if one may judge from what happened in the artificial nests. The eggs were not laid at regular intervals but in bursts, during which three or four eggs were laid with comparative rapidity. Over an extended period the rate of egg-laying averaged out to one egg every forty-eight hours. At a temperature around $70^{\circ} \mathrm{F}$. most of the eggs developed into larvae in 25 days. The larval period was about 55 days. Observations had to be discontinued before any of the pupae transformed to adults but, if the pupal period is as long as the larval period, the development of a texanus worker from egg to adult should have taken not less than four and a half months in the artificial nests. If this slow rate of brood development is true of free colonies of texanus, it is easy to appreciate why this species is pleometrotic. Unless several queens were present in each colony the production of adults could scarcely keep pace with the inevitable attrition of the foraging workers.

After the ants were installed in the aquaria nests they would not eat anything, not even the food on which they had gorged themselves while in the Janet nests. As already noted the texanus crawled over the oak leaves by the hour and occasionally drank from droplets of water that condensed on the walls of the aquaria. But for a period of several weeks they were not seen to swallow anything else. If the 
ants had died it would have been logical to conclude that they had starved, but they did not die. On the contrary they seemed to be in better shape than when they had been feeding on honey in the Janet nests. While the ants were in the Janet nests they had been given pieces of live-oak leaves on the chance that they might secure some nutricious secretion from them. The ants were definitely attracted to the leaf fragments and stripped off the small, stellate hairs which occur on the petiole and the lower surface of the blade. In the leaf of Q. emoryi Torr., the species mainly used in this $s \mathrm{dudy}^{2}$, the largest and most conspicuous stellate hairs are concentrated at the base of the blade where they form a dense, tangled mat at either side of the midrib. These matted hairs often shelter small mites and it was at first believed that the ants were stripping off the hairs to get at the mites. Further examination showed that this was untrue for, after removing the stellate hairs, the ants discarded both the hairs and the mites which were among them. This led to a series of efforts, all of which failed, to secure an extract from the hairs which would be acceptable to the ants. Instead of attracting the ants, such extracts usually repelled them. But this did not eliminate the possibility that the ants might somehow be securing food from the stellate hairs and their actions in the aquaria nests seemed to strengthen this possibility.

The oak twigs in the aquaria were sealed into small jars of water and usually remained fresh for ten days or more. During this period the buds on many of the twigs would unfold and small, new leaves would be displayed. If the ants were securing food from the stellate hairs, it might be expected that the hairs of the young leaves would be particularly attractive. It was, therefore, a surprise to discover that the ants paid much less attention to the young leaves than they did to the old ones. Subsequent events provided an explanation for this behavior, but its significance was not appreciated when it was first observed.

About March 8th choke-cherry trees near the laboratory began to leaf out and a day or two later willow bushes began to produce catkins. Twigs from these plants were substituted for the live-oak twigs in the aquaria largely, it must be confessed, as a desperation measure. As

\footnotetext{
${ }^{2}$ It may be objected that $Q$. emoryi is unsuitable for this work since its range lies well to the west of that of texanus. Admittedly it would have been preferable to use the leaves of $Q$. virginiana, as most of the nests of texanus have been found in this oak. Although texanus could not nest in $Q$. emoryi under normal conditions, its western counterpart, Cryptocerus rohweri Wh. does so. On November 7, 1952, the writer took a small colony of rohweri that was nesting in Q. emoryi at Peña Blanca Springs, Santa Cruz Co., Ariz.
} 
soon as the texanus workers began to forage over these twigs it was obvious that they were feeding. They spent much time licking the tips of some of the bud scales of the choke-cherry twigs. An examination of these showed that each of the inner scales possesses two oval nectaries at its tip. The nectaries produce a fluid which the ants collected. It is possible that nectar was also gathered from the willow catkins but the obvious thing that the ants took from these was pollen. Their liking for pollen was clearly demonstrated, for they would not only take it from the catkins but would also spend long hours picking up pollen grains that had fallen onto the sides and floor of the aquarium. When the pollen was collected from the sides of the aquaria the process was easy to observe but, despite much effort, the writer was never able to determine how the grains are initially picked up. It is probable that they are formed into clusters by the palps, for the mandibles appear to be closed throughout the process. When a number of grains have been formed into a cluster this is incorporated into a drop of liquid at the end of the hypopharynx. After a short period during which the pollen-filled drop is juggled about at the end of the hypopharynx, the drop is swallowed.

As the spring advanced other trees and shrubs came into bloom and as each did so twigs with blossoms were placed in the aquaria with the texanus workers. It was soon clear that not all pollen is equally acceptable to texanus. Although the ants crawled over blossoms of apples, plums and Oregon holly (Mahonia sp.) whose anthers were loaded with pollen, they paid no attention to the pollen or to the anthers which bore it. Conversely, they were strongly attracted to the pollen of the box elder (Acer negundo L.) and that of the live-oak $Q$. emoryi. The reaction of the ants to the live-oak catkins or to the box elder stamens was exactly that which they had shown with the willow catkins; pollen was collected directly from the catkins or anthers and also from other areas where it had settled. This last response suggested that under natural conditions the ants may secure much of their pollen supply not from the blossoms but from other parts of the plant. If they prefer wind-borne pollen, as seems to be the case, why might not their constant foraging over the surface of the leaves be a search for pollen grains adhering to the leaf? The difficulty in proving this lies in the fact that over most of the leaf the pollen grains are so widely scattered that their detection is difficult, even under high magnification. But a careful examination of the leaves of $Q$. emoryi showed that a considerable concentration of pollen grains is often present in the two tangled mats of stellate hairs at the base of the midrib. A great many 
dust particles are also trapped in these mats and earlier examinations had failed to distinguish between the dust particles and the pollen grains. But since pollen grains are often present in the basal hair mats on the leaves of $Q$. emoryi, the stripping of the hairs by the texanus workers becomes understandable. The hairs are removed in the process of extracting pollen grains from among them and after the pollen grains are extracted the hairs are discarded. Further, if a leaf contains no pollen grains the ants should not be overly interested in it. An excellent example of this had been furnished by the young oak leaves which unfolded in the aquaria. Since these leaves had developed in a sealed space they contained no pollen and as a result the ants paid scant attention to them. In addition, the pollen-gathering activities of texanus offer an explanation of their preference for nests in liveoaks. This preference was pointed out in our 1954 study but no attempt was made to account for it. Stellate hairs are present on the under surface of the leaves of most live-oaks. Their arrangement is highly variable. In $Q$. hypoleucoides Cam., the "silverleaf oak", these hairs give rise to the common name for the plant, since they form a dense, silvery, tomentose layer over the entire lower surface of the leaf. In $Q$. emoryi, as already noted, most of the stellate hairs are concentrated at the base of the blade. But whatever the arrangement, these hairs function with great efficiency as pollen traps, for they are sufficiently sticky to hold pollen grains with surprising tenacity. In one instance the leaves of $Q$. hypoleucoides were evenly coated with willow pollen over the entire lower surface. After the pollen had adhered to the stellate hairs no amount of shaking would dislodge it, but it is interesting to note that when these pollen coated leaves were placed in the aquaria the texanus workers completely cleared them of pollen in a few hours. It is even more interesting to consider the advantages of such a pollen trap to a pollen feeder. The catkins of live-oaks are produced in the spring and remain on the trees for a few days only. The period during which pollen can be taken directly from the catkins is, therefore, a comparatively brief one. Unless texanus could store pollen, and there is no evidence that it does so, it could not live on pollen taken directly from the catkins. This seemed so obvious that pollen was not even considered as a possible source of food in our I954 study. But while texanus does not store pollen the leaves of live-oak trees do. Moreover, this storage is not selective but includes any wind-borne pollen. Thus when texanus nests in live-oak trees it is assured of a lasting supply of pollen trapped in the stellate hairs on the lower surface of the leaves. 
Since texanus does not always nest in live-oaks it is clear that only a part of the picture has been presented here. The nectar-feeding activities of texanus, of which one instance was cited in this study, offer interesting possibilities for further investigation. If texanus feeds on nectar there is every reason to suppose that it will also feed on honey dew. This opens a wide range of possible food sources including the surface secretions of galls and the sugary exudates of coccids and aphids. But it now seems reasonably certain that texanus does not ordinarily augment its nectar-pollen diet with the tissues of other insects. This behavior is noteworthy, for many other ants which obtain the major part of their diet from plant sources (the harvesters and the honey ants) show no hesitation about feeding on the tissues of other insects as a supplementary item of diet. But the nectar-pollen diet of texanus is no more specialized than the ant itself. For the structure of texanus, like that of most of the members of the Cryptocerini, is highly specialized and it is not surprising that an ant with such advanced structural features should have an unusual and restricted diet.

\section{Literature Cited}

1. Creighton, W. S., and R E. GregG 1954. Psyche, 61 (2): 41-57.

2. Creighton, W. S.

1953. Psyche, $60(2): 82-84$. 

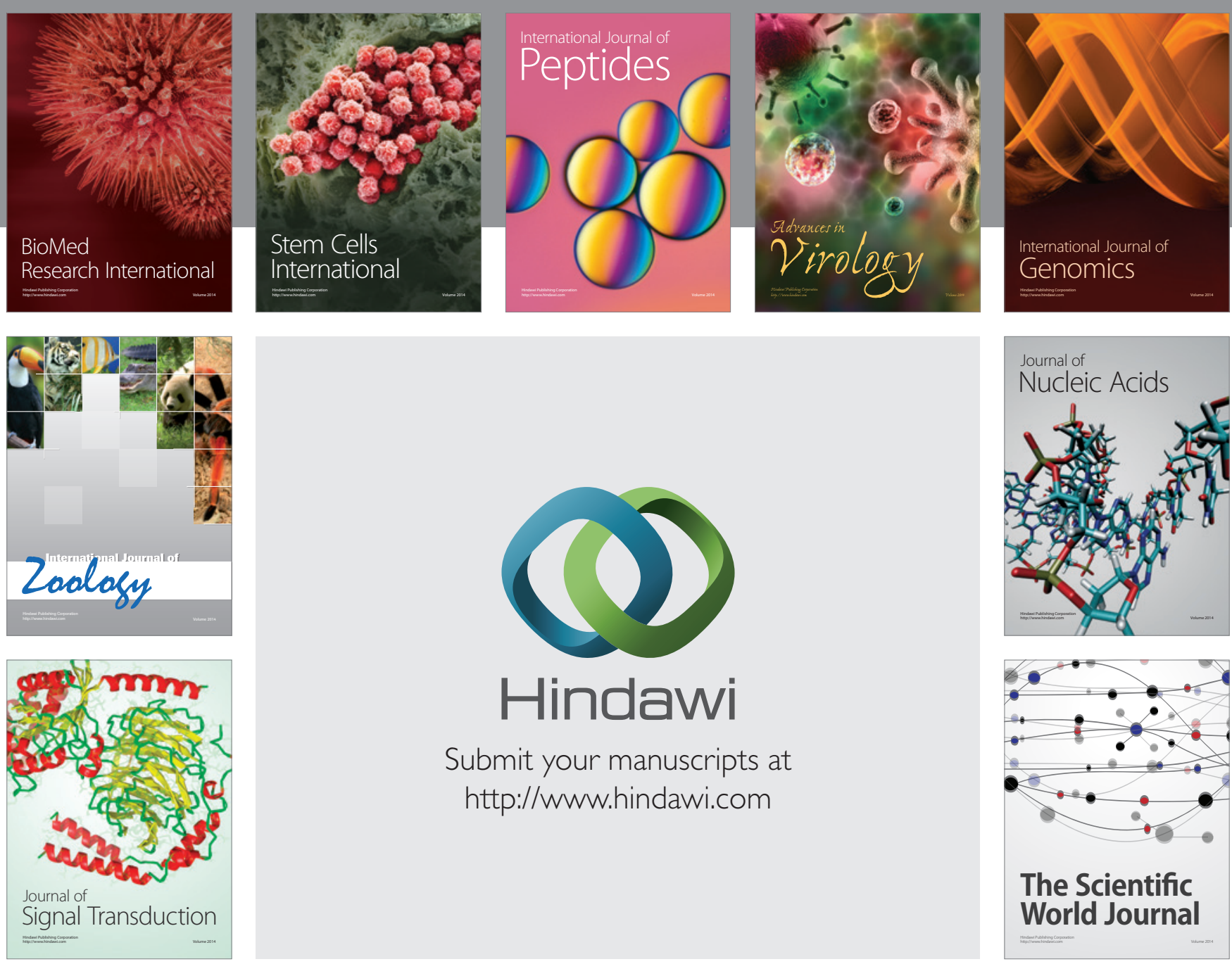

Submit your manuscripts at

http://www.hindawi.com
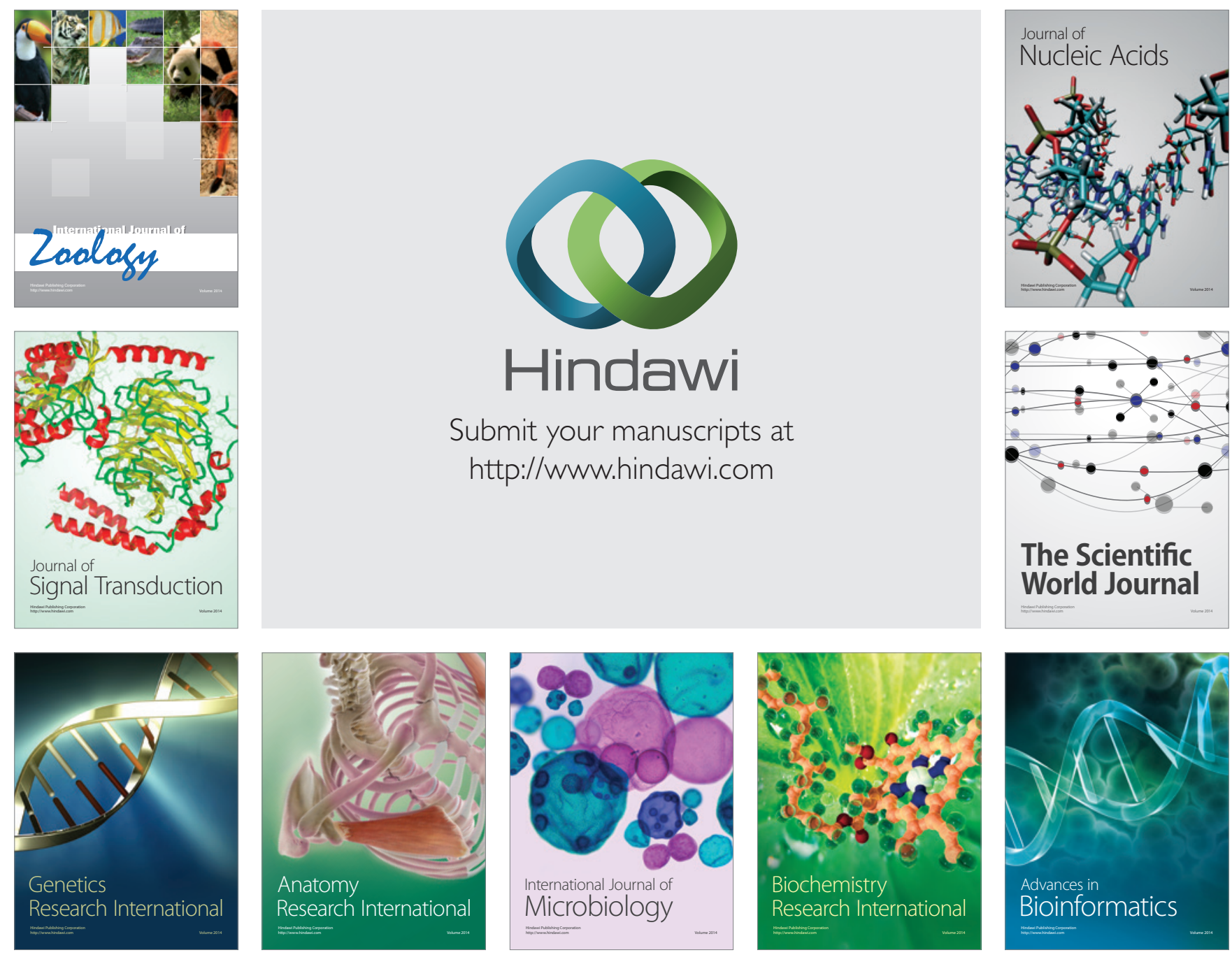

The Scientific World Journal
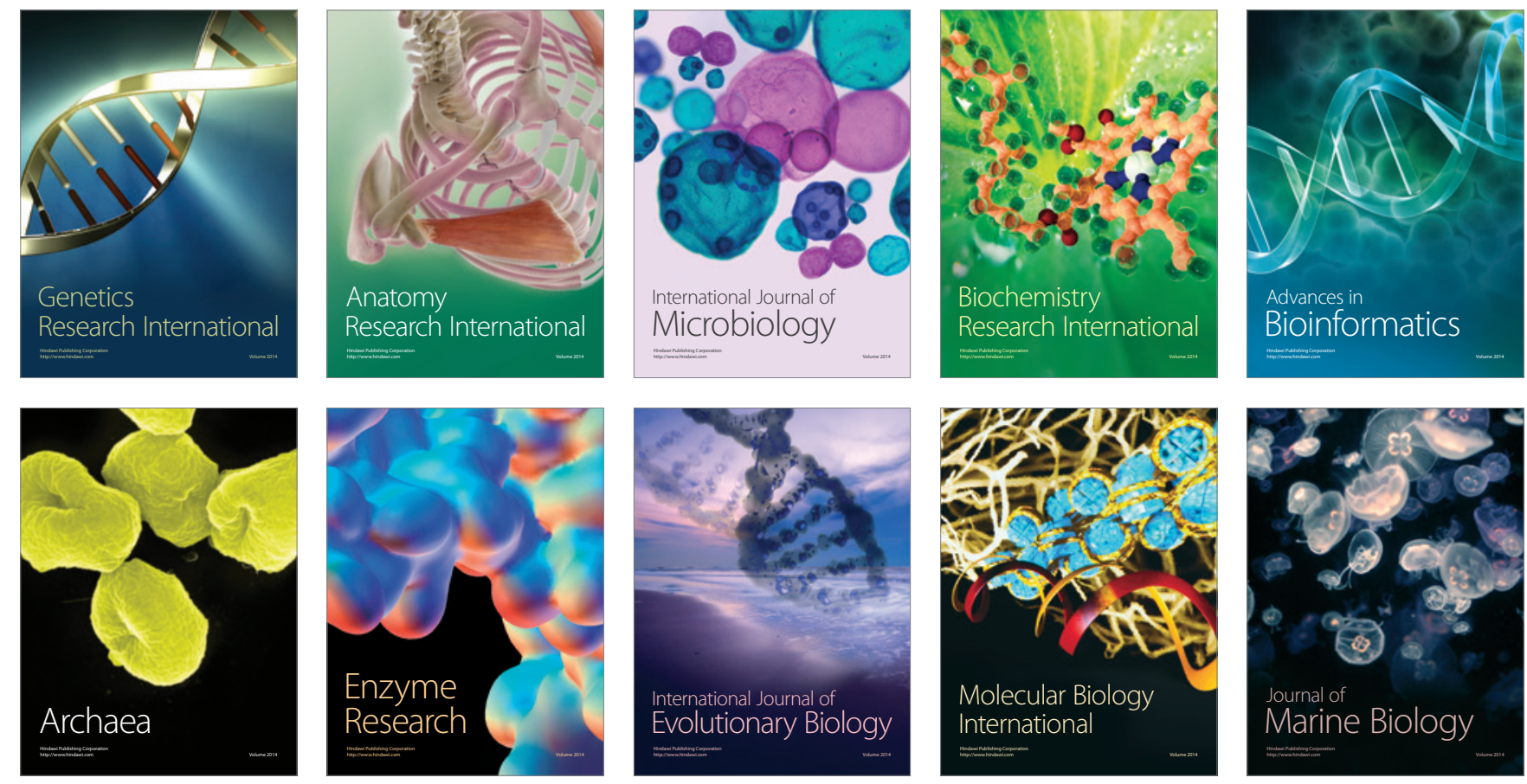